\title{
Antropologia e sociobiologia: breve crônica sobre a ressureição de um debate
}

DOI

http://dx.doi.org/10.11606/ 2179-0892.ra.2018.145512

\section{Lorenzo Macagno}

- Universidade Federal do Paraná / Curitiba, PR, Brasil

$\boldsymbol{\nabla}$ lorenzom@ufpr.br

\section{RESUMO}

No final de 2016, um Requerimento emitido por membros de uma Comissão Parlamentar de Inquérito (CPI), conhecida como CPI FUNAI-INCRA 2, solicitou a quebra de sigilo bancário e fiscal da Associação Brasileira de Antropologia ( $A B A)$, bem como do seu presidente. Para fundamentar as acusações contra a $A B A$, o Requerimento citou, em uma de suas passagens, argumentos de Napoleon $A$. Chagnon, dentre os quais a afirmação de que os antropólogos brasileiros não fazem ciência, mas ativismo. Chagnon foi um dos poucos antropólogos a adotar os postulados da chamada sociobiologia. Com a evocação do nome de Chagnon, o Requerimento da CPI estava, involuntariamente, "ressuscitando" um debate moribundo: antropologia versus sociobiologia. A partir do cenário acusatório montado pela CPI FUNAIINCRA 2, este artigo retoma aquela controvérsia fundamental que, desde a década de 1970, dividiu antropólogos e sociobiólogos. 
My modest conclusion is that Western civilization has been constructed on a perverse and mistaken idea of human nature. Sorry, beg your pardon; it was all a mistake. It is probably true, however, that this perverse idea of human nature endangers our existence.

Marshall Sahlins,

The Western Illusion of Human Nature, 2008.

Todos os aqui presentes sabem que esta convocatória foi feita em circunstâncias muito singulares para a antropologia no Brasil: 2017 foi um ano em que assistimos a um desfecho particularmente preocupante' ${ }^{1}$. Refiro-me, concretamente, ao indiciamento de 21 antropólogos e antropólogas por parte de uma Comissão Parlamentar de Inquérito (CPI). Estes colegas estão sendo acusados de supostos "conluio", "falsidade ideológica" e "parcialidade" na produção de estudos técnicos de delimitação de territórios e de laudos que subsidiam a demarcação de terras indígenas e quilombolas. Esse bojo de acusações veicula, ademais, toda uma cosmologia da suspeita sobre supostas irregularidades que teriam envolvido a Fundação Nacional do Índio (FUNAI) e o Instituto Nacional de Colonização e Reforma Agrária (INCRA). Nessas circunstâncias, antropólogas e antropólogos se tornam suspeitos, pelo simples fato de terem assumido os imperativos metodológicos para a elaboração de laudos, cujas técnicas foram, aliás, cuidadosamente delimitadas no chamado "Protocolo de Brasília" (ABA, 2015) e pelo fato de terem assumido os imperativos éticos resultantes não só do código de ética da Associação Brasileira de Antropologia (ABA) senão, também, dos mandatos da constituição brasileira de 1988. O Convênio entre o Ministério Público Federal e a própria $A B A$, que se molda pelo princípio da qualificação dos antropólogos chamados a produzir laudos e estudos técnicos, passa a ser razão alegada para acusação contra a ABA. Mas as acusações não se limitam aos antropólogos, sejam professores universitários, atuem em organizações não governamentais ou atuem como servidores públicos; também integram a lista de acusados missionários, demais servidores públicos e outros profissionais. Trata-se de um fato inédito, e que atinge a todos nós.

É publicamente sabido, ademais, que os deputados que, em agosto de 2016, criaram essa CPI (que veio a ser conhecida como CPI-FUNAI e INCRA 2) representam os interesses da Frente Agropecuária Parlamentar². Esta investida é, na verdade, parte de um segundo momento, cujo antecedente foi uma outra $\mathrm{CPI}$, criada em outubro de 2015, a instancias do então Presidente da Câmara dos Deputados Eduardo Cunha (PMDB, RJ) $)^{3}$. Todo este processo teve um impacto público e foi abordado e discutido nos mais diversos âmbitos, incluindo nas chamadas redes sociais. É claro que, por motivos óbvios, a ABA se viu obrigada a intervir publicamente. Alguns de nós que não trabalhamos diretamente com
1 Mesmo que este texto nasça de uma intervenção em uma das Sessões do Foro "Quem tem medo dos(as) antropólogos(as)?" realizado em outubro de 2017 (no 41 ${ }^{\circ}$ Encontro Anual da ANPOCS, Caxambu), muitas das reflexões aqui apresentadas são oriundas de um diálogo que travei com meus alunos de doutorado no Programa de Pós-Graduação em Antropologia da UFPR. Discutimos, ao longo do $2^{\circ}$ semestre de 2017, em um Seminário Avançado de Teoria Antropológica por mim ministrado, várias das críticas antropológicas à sociobiologia. Gostaria, pois, de agradecer a Carusa Gabriela Dutra Biliatto, Magda Luiza Mascarello, Rodrigo Souza Fontes de Salles Graça e Sara Guerreiro Parada.

2 Foi em 30 de agosto de 2016 que a Presidência da Câmara dos Deputados deu conhecimento à plenária a criação desta CPI. Ver: http://www2.camara.leg.br/ atividade-legislativa/comissoes/ comissoes-temporarias/ parlamentar-de-inquerito/55alegislatura/cpi-funai-e-incra-2/ conheca-a-comissao/5. AtodeCriaodaCPI.pdf.

3 Os detalhes da instauração, bem como dos desdobramentos, daquela "primeira" CPI FUNAI INCRA foram abordados por Julia Marques Dalla Costa, Roberto Alves de Almeida e Fernanda Silveira Anjos em um trabalho apresentado na $30^{\circ}$ Reunião Brasileira de Antropologia, em João Pessoa, agosto de 2016. 
assuntos relacionados às questões indígenas ou às comunidades quilombolas, $\mathrm{e}$ que circunstancialmente integramos a diretoria da $A B A$, temos, penso, a obrigação de exercer uma vigilância epistemológica sobre os efeitos que essas acusações e contra-acusações provocam.

Não me alongarei nos detalhes que são conhecidos por todos. A atual conjuntura dos desafios enfrentados pelas políticas indígenas e quilombolas, perante as investidas do extrativismo e do agronegócio, tem sido recentemente descrita por Manuela Carneiro da Cunha (2017). Seu artigo, publicado na sessão de discussões da revista HAU-Journal of Ethnographic Theory, foi enriquecido com comentários de vários colegas do Brasil e do exterior. Sem dúvidas, o título do Foro que nos reúne é mais que oportuno e premente: "Quem tem medo dos antropólogos(as)?”. A resposta parece autoevidente. No entanto, para além desta questão pontual e óbvia, o que pretendo realizar nesta ocasião é uma breve reflexão sobre um conjunto de acusações mais genéricas que pesam sobre o fazer antropológico. Ou seja, considero que é imperioso situar as acusações contra a antropologia, presentes no requerimento FUNAI-INCRA $2 \mathrm{~N}^{\circ} 86 / 2016$, em um sistema de desqualificações mais amplo. O denominador comum dessas desqualificações se apoia na crença de que a maioria dos antropólogos e antropólogas no Brasil não fazem ciência, mas militância, ativismo ou política. Sendo assim, o corolário de tudo isso se reduz à nossa suposta falta de imparcialidade. Duas constatações quase óbvias sobre o teor dessas alegações. 1. Elas não são novas, já que não é a primeira vez que aparecem na nossa história disciplinar. Ou seja, no passado, e em outras latitudes, antropólogos e antropólogas foram suspeitos, por motivos diversos, de ameaçar algum tipo de poder ou interesse específico. 2. Essas acusações nunca foram absolutas, mas relativas. Dito de outra forma, quando nos colocamos a pergunta "Quem tem medo dos antropólogos(as)?", a resposta - e devo empregar aqui alguns termos recorrentes em nosso jargão - é situacional, contrastiva, relacional. Ou seja, de que antropólogos estamos falando? Em quais circunstâncias? Onde? Como? Quando?

Tal como ensinamos nossos alunos iniciantes, durante o período da descolonização africana quem tinha "medo" dos antropólogos - neste caso, em virtude de uma suposta cumplicidade com o colonialismo-eram as emergentes elites nacionalistas africanas. Mas, quando a pergunta se coloca no Brasil de hoje, a resposta obviamente adquire outro sentido.

De qualquer modo, e fazendo um brevíssimo parêntese, é preciso lembrar que na década de 1950, no período das descolonizações africanas, nem todos os antropólogos mereciam a acusação de colaboracionismo com as administrações coloniais. Chamo a atenção, de modo breve, sobre o caso do antropólogo norte-americano Marvin Harris, fundador do materialismo cultural. Em 1957, Harris foi expulso de Moçambique pelas autoridades coloniais portuguesas, em virtude 
das suas pesquisas de campo sobre a exploração da força de trabalho africana. Essas pesquisas, certamente, incomodavam e ameaçavam o regime ${ }^{4}$. Apesar de criticado em virtude, sobretudo, do seu determinismo materialista, Harris (1978; 1979) teve o mérito de ser-junto com Marshall Sahlins - um dos primeiros antropólogos norte-americanos a enfrentar as correntes da chamada sociobiologia. Mas, por que evocar neste contexto singular a crítica antropológica à sociobiologia? Qual a sua relação com o Requerimento da CPI FUNAI-INCRA 2?

Em 2016, o requerimento de quebra de sigilo bancário e fiscal da $A B A$, emitido pelos membros da $\mathrm{CPI}$, foi acompanhado de um documento de 89 páginas. Um dos trechos mais significativos desse requerimento é a utilização dos argumentos do antropólogo e sociobiólogo Napoleon A. Chagnon, com o intuito de fundamentar a acusação contra a ABA. Mais especificamente, o documento cita uma entrevista que o jornal Folha de São Paulo realizou com Chagnon no início de 2015, e na qual ele afirma, dentre outras coisas, que os antropólogos brasileiros não fazem ciência, mas ativismo 5 . Eis a afirmação que consta entre as páginas 48 e 49 do Requerimento da CPI-FUNAI-INCRA 2 Nº 86/2016:

O comprometimento ideológico e político da corrente dominante na antropologia brasileira, que é promovido pela $A B A$, já foi alvo de considerações pelo polêmico e criticado antropólogo norte-americano Napoleon A. Chagnon, que passou a ser execrado pela corrente antropológica que segue a $A B A{ }^{6}$

A história é longa e tem suas nuances. Mas, para sermos fiéis aos fatos, é preciso dizer que a "execração" à obra de Chagnon começou, na verdade, no seio da própria comunidade antropológica norte-americana e, mais especificamente, no seio da American Anthropological Association. Como no mito grego da Hidra de Lerna - a serpente cujas cabeças voltavam a se regenerar após serem cortadas - o debate "antropologia/sociobiologia" renasce, mais uma vez, em um novo contexto, graças às alegorias contidas no requerimento de uma CPI.

É preciso lembrar que a sociobiologia surge em meio a uma série de novas controvérsias que aconteceram no seio da biologia evolutiva. Os sociobiólogos postularam diversas explicações para o chamado fenômeno do altruísmo, ou comportamento do "autosacrifício", observado em algumas sociedades de insetos, como no caso das abelhas ou de formigas estéreis que, antes de morrerem, ajudam a rainha a se reproduzir. Como explicar o altruísmo sem abandonar os princípios básicos do paradigma darwiniano? Até a chegada dos sociobiólogos, as explicações consensuais no campo da biologia evolutiva se baseavam na "seleção grupal", mas sempre privilegiando o indivíduo como perpetuador dos genes. Ao invés da seleção grupal, os sociobiólogos propuseram a "seleção por parentesco". Segundo os sociobiólogos, e em virtude
4 Interessei-me particularmente pela trajetória de Marvin Harris em virtude, sobretudo, do meu trabalho de campo em Moçambique. Harris foi o primeiro antropólogo profissional a escrever sobre o chamado Regime de Indigenato e sobre a questão dos "assimilados" em Moçambique - um assunto que foi tema dos meus trabalhos de mestrado e doutorado.

5 Ver entrevista com Napoleon A. Chagnon, realizada por Ricardo Mioto: "Antropólogos, índios e outros selvagens", Suplemento Ilustríssima. Folha de São Paulo, 22-02-2015. Disponível em: http://www1.folha.uol.com.br/ ilustrissima/2015/02/1592344antropologos-indios-eoutros-selvagens.shtml

6 O Requerimento FUNAIINCRA $2 \mathrm{~N}^{\circ} 86 / 2016$ pode ser consultado na íntegra em: http://www.camara.gov. br/proposicoesWeb/prop_ mostrarintegra;jsessionid $=0506589$ EDD4255B71 $3 \mathrm{Co8} \mathrm{CB} 95 \mathrm{C} 9 \mathrm{~A} 20 \mathrm{~B} 4$.proposi coesWebExterno2?codteor= 1517569\&filename $=$ Tramita cao-REQ+86/2016+CPIFUNA $2+\% 3 \mathrm{D} \% 3 \mathrm{E}+\mathrm{RCP}+26 / 2016$ 
de uma combinatória bio-comportamental, há em algumas sociedades de insetos "indivíduos" que, graças a determinados genes, comportam-se mais favoravelmente em relação aos parentes do que aos estranhos. Desse modo, os indivíduos maximizam a "adaptação inclusiva" (inclusive fitness) e seu "sucesso reprodutivo" quando se sacrificam pelos "seus". Quase como em um nepotismo biológico, o benefício do parente próximo, perpetrado pelo ato altruísta, garante que os "genes de sacrifício" possam ser "incluídos" com sucesso nas futuras gerações. O corolário desta explicação sociobiológica consiste em postular que, na verdade, a aparência do "altruísmo" comportamental mascara a essência de um "egoísmo" genético.

Napoleon A. Chagnon foi, de fato, um dos poucos antropólogos que, na década de 1970, aderiu às teorias da sociobiologia formuladas pelo biólogo e entomólogo Edward O. Wilson, especialista no estudo do comportamento das formigas ${ }^{7}$. Chagnon pretendia utilizar a sociobiologia para explicar suas teorias sobre a poliginia, o sucesso reprodutivo e a violência entre os Yanomami. Para dizê-lo em seus próprios termos, seu trabalho se apoiava na ideia de que

\section{(...) todo o propósito e o esquema das estruturas sociais tribais parecem destina- dos a controlar o acesso sexual dos homens às mulheres núbeis, em idade repro- dutiva. O propósito ou a função da "organização social" nas tribos (e em muitos animais não humanos) parece ser a regulação eficiente do acesso sexual dos machos às fêmeas e do papel das coalizões masculinas nesse processo (Chagnon, 2014: 250, a ênfase é original).}

Uma das grandes polêmicas - já que houve várias - em torno da sua pesquisa eclodiu em 1988, quando Chagnon publica um artigo na revista Science intitulado "Life Histories, Blood Revenge, and Warfare in a Tribal Population". Esse artigo pretendia demostrar, a partir de uma série de dispositivos biométricos e estatísticos, que os homens yanomami que exerciam mais violência no seio da sociedade (os unokai, guerreiros que efetivamente tinham matado alguém) eram, também, os que tinham maior sucesso conjugal e reprodutivo. Imediatamente, dois importantes jornais brasileiros repercutiram tal "descoberta". A "boa-nova" espalhou-se aos quatro cantos: agora, a violência dos índios podia ser comprovada "cientificamente"! Em um contexto de reivindicação de direitos territoriais e negociações complexas com a FUNAI, a construção dessa imagem estigmatizadora veiculava perigosos ingredientes políticos. Por isso, a reação da ABA não se fez esperar. Na época, uma carta de repúdio, assinada por Manuela Carneiro da Cunha (1989), e publicada na Anthropology Newsletter (boletim oficial da American Anthropological Association), advertia sobre os riscos éticos de atribuir aos Yanomami o mote de "povo feroz". Em sua réplica, Chagnon se mostrou incomo-
7 Uma discussão entre Edward O. Wilson e Marvin Harris foi publicada na revista Society em 1978. O debate foi mediado por Ann Carroll. Ver: "Heredity versus Culture: A Debate", Society, vol. 15, 1978, pp. 60-63. 
dado com o fato de que a American Anthropological Association tivesse concedido espaço para este tipo de reclamações promovidas por associações antropológicas estrangeiras. Tais questionamentos por parte da ABA eram, segundo Chagnon, mais "políticos" que "científicos" (Chagnon, 1989: 24). Quase simultaneamente, Alcida Rita Ramos e Bruce Albert (1989) enviaram à mesma revista Science um comentário crítico repudiando as conclusões do artigo de Chagnon (ver, também, Ramos, 2004).

A cada nova polêmica, a contrarreação de Chagnon consistia em repetir o mesmo mantra acusatório: os antropólogos padeceriam da síndrome da "biofobia". Uma acusação leviana, já que os antropólogos criticaram as teses da sociobiologia não por desconfiarem da biologia ou das teorias da evolução biológica. O motivo dessas críticas era que, por detrás do manto da neutralidade científica, a sociobiologia acabava assumindo - nas palavras de Marshall Sahlins (1976-a forma de um novo pensamento totêmico. Para dizê-lo de outra forma, a sociobiologia passa a veicular uma nova cosmologia da ideologia utilitarista e individualista da sociedade ocidental através da genetização da cultura (neste caso, para imaginar um Homo bellicus yanomami).

É preciso dizer, no entanto, que os antropólogos não foram os únicos a questionar a sociobiologia. As maiores disputas surgiram no seio da própria biologia e, mais especificamente, no seio da chamada biologia evolutiva (Marks, 1980). É enganosa, portanto, a oposição "ciência" (sociobiológica) versus “ideologia" (antropológica). Inclusive no Brasil, alguns biólogos não duvidaram em expressar publicamente suas críticas à sociobiologia ${ }^{8}$. Importa ressaltar que, independentemente das "venturas e desventuras" de Napoleon A. Chagnon na Amazônia, antropólogos e antropólogas brasileiros têm se preocupado em compreender os alcances da sociobiologia e suas implicações para o saber antropológico. Chamo a atenção, nesse sentido, para o trabalho crítico e de divulgação de Gláucia Oliveira da Silva (1993; 2006), do Departamento de Antropologia da Universidade Federal Fluminense (UFF).

Amparados em extensas pesquisas empíricas - sobretudo no campo dos estudos do parentesco - os antropólogos alertaram sobre os riscos perversos da sociobiologia. Um desses riscos reside na tentação de pretender explicar diferenças comportamentais a partir de diferenças biológicas. Justamente, ao retratar os "machos como sexualmente indiscriminantes" e as fêmeas como "seletivas", os sociobiólogos (e o próprio Chagnon) expuseram-se à crítica de estarem reproduzindo os estereótipos ocidentais concernentes ao papel dos sexos. Não se trata de negar a importância que a chamada "seleção por parentesco" ou a "inclusão genética adaptativa" possam ter em organismos simples como os de alguns insetos. Mas a luz amarela se acendeu quando os sociobiólogos postularam a aplicabilidade da sociobiologia ao comportamento das sociedades humanas.
8 Vale a pena uma consulta à postagem: "Edward Wilson e o fím da sociobiologia" no blog do biólogo Nélio Bizzo. Disponível em: http:// blogdobizzo.blogspot.com. br/2012/06/edward-wilson-eo-fim-da-sociobiologia.html 
Logo, ao mesmo tempo em que a antropologia é alvo de uma série de acusações, estamos assistindo, também, ao ressurgimento de um debate que parecia enterrado. $O$ debate aparentemente superado sobre a sociobiologia ressurge, pois, quase que sorrateiramente: em um requerimento da CPI FUNAI-INCRA. Parece-me que os assessores deste grupo de deputados não tomaram um caminho muito acertado ao optar pelo nome de Napoleon A. Chagnon para legitimar a crença-ou a acusação - de que os antropólogos brasileiros fazem ideologia ao invés de ciência. Por outro lado, com a evocação do nome de Chagnon, eles, de alguma maneira, importaram um debate que já estava presente na antropologia norte-americana há várias décadas.

A crítica à sociobiologia teve início na segunda metade da década de 1970. Seu ápice foi, tal como adiantamos, quando Marvin Harris lançou suas críticas devastadoras a Napoleon Chagnon e a Edward O. Wilson, o pai fundador da sociobiologia9. Costem ou não os sociobiólogos, Marvin Harris é defensor de um paradigma científico e, atrever-me-ia a dizer, positivista, na antropologia. A partir de outra perspectiva diferente da de Harris, Marshall Sahlins lançou, em 1976, outra crítica contundente ao paradigma sociobiológico em seu livro intitulado, justamente, The Use and Abuse of Biology. An Anthropological Critique of Sociobiology.

Passaram-se os anos e os ânimos pareciam se acalmar. Até que em 2000, o jornalista Patrick Tierney publicou um volumoso livro contra Chagnon e contra o geneticista James Neel, bem como contra outros antropólogos que trabalharam entre os Yanomami. O livro, Darkness in El Dorado: How Scientists and Journalists Devastated the Amazon ${ }^{10}$, criou uma imensa reviravolta no seio da American Anthropological Association. Milhares de páginas de acusações e contra-acusações foram escritas sobre o assunto ${ }^{11}$. Anos depois, o próprio Chagnon reconheceria que a razão principal do escândalo era que sua “...crença em que a natureza humana tem uma evolução biológica-aquilo que Edward O. Wilson chamou de 'sociobiologia' - era inaceitável para a maioria dos antropólogos culturais e outros acadêmicos" (Chagnon, 2014: 507). Sua autodefesa é infundada. Não é a "evolução biológica" que está em questão, mas os deslizes éticos que Chagnon parece ter cometido em sua pesquisa de campo. Em 2013, o debate "antropologia versus sociobiologia" estava mais vivo do que nunca. Naquele ano, a Academia Nacional de Ciências, nos Estados Unidos, decide nomear Napoleon A. Chagnon como membro de uma das suas sessões. Imediatamente, Marshall Sahlins, velho oponente de Chagnon e membro, desde 1991, dessa mesma Academia, apresenta a sua renúncia. O gesto de Sahlins teve um duplo motivo ético: repudiar a nomeação de Chagnon e manifestar seu desacordo com os "projetos de investigação militares" (a serviço da política exterior norte-americana) levados a cabo pela Academia Nacional de Ciências (Price, 2013).

Após a publicação do livro de Patrick Tierney sobre o affaire Chagnon e sua
9 A monumental obra de Wilson, publicada em $1975 \mathrm{e}$ intitulada Sociobiology. The New Synthesis, possui 27 capítulos e quase setecentas páginas. É no último capítulo, intitulado "Man: From Sociobiology to Sociology", que Wilson constrói seus argumentos para pensar a sociobiologia como um paradigma aplicável às ciências sociais.

10 A versão em português do livro de Tierney (Trevas no Eldorado, publicada pela Ediouro em 2002) recebeu uma ponderada resenha de Ricardo Ventura Santos. Ver "Os Yanomami e a polêmica dos antropólogos". Disponível em: https://pib.socioambiental. org/es/noticias?id=5060

11 Para acompanhar parte dessa volumosa controvérsia recomendo a consulta do link "Darkness in El Dorado" da página pessoal de Douglas W. Hume. Disponível em: http:// anthroniche.com/darknessin-el-dorado-controversy/ archived-resources/ 
equipe, as reações foram inúmeras. Nem sequer o "hermenêutico" Clifford Ceertz conseguiu permanecer impassível. Em 2001, Geertz fez uma animada intervenção no New York Review of Books sobre o livro de Tierney. Em sua resenha enumerava, ironicamente, uma lista interminável de adjetivos que pesam sobre aqueles antropólogos que se atreveram a criticar o trabalho de Chagnon e seu paradigma sociobiológico (qualquer semelhança com a "nossa" realidade não é mera coincidência): “...'marxistas', 'mentirosos', 'antropólogos culturais da esquerda acadêmica', 'aiatolás', 'altruístas politicamente corretos', 'pacifistas', 'antropólogos fracos com medo de enfrentar a [Igreja]', 'moralizadores pós-modernos anticientíficos'..." (Ceertz, 2015 [2001]: 148). Por vezes-e no pior dos casos - o antropólogo que ousasse criticar os pressupostos da sociobiologia se arriscaria a ser rotulado de obscurantista.

Seria um pleonasmo relembrar que, pelo menos desde a década de 1950, com a publicação de "Raça e história" de Lévi-Strauss, os antropólogos celebram as descobertas da genética, da paleoantropologia e da biologia evolutiva. Gregory Bateson, como sabemos, fez memoráveis reflexões sobre o comportamento humano e não humano em diálogo com seus colegas etólogos e em sintonia com as descobertas da cibernética e da teoria da comunicação. Acusar os antropólogos de obscurantismo, ou de "biofobia", como fez Chagnon, é deturpar uma parte significativa da nossa história disciplinar. O que os antropólogos questionaram não é a biologia em si, mas os postulados acerca da existência de uma suposta "natureza humana" implícita nas noções de altruísmo e egoísmo genético ou nas noções de "adaptação inclusiva" promovidas pela sociobiologia. Logo, a violência, as relações de gênero, as desigualdades sociais, as relações de parentesco não são redutíveis a qualquer "natureza".

Ao que parece, alguns biólogos especialistas em primatas estão, nestes momentos, à procura do que, com muitas aspas, denominam a "molécula do apego": a oxitocina 1.0. Trata-se de um hormônio que, supostamente, seria o encarregado de desenvolver o instinto paternal em algumas espécies de saguis. Mais uma vez a caixa de Pandora é aberta, deixando escapar velhas artimanhas. O instinto é "dado" biologicamente ou se "constrói" culturalmente? Inevitavelmente, tudo isso cria um grande fascínio para um público diverso, sobretudo quando tais discussões aparecem nos suplementos de divulgação científica dos jornais ${ }^{12}$. No entanto, a luz de alerta se acende quando determinadas "descobertas" se incorporam ao senso comum vulgar e, sob o efeito de uma reflexividade ad infinitum, passam a ser utilizadas como metáforas explicativas do comportamento das sociedades humanas.

Por outro lado, e independentemente da vontade dos seus respectivos protagonistas, muitos dos postulados vulgares da sociobiologia-sobre o papel dos sexos, da família, da reprodução, da violência-já parecem circular nos debates
12 Ver, a respeito, a nota do divulgador científico Reinaldo José Lopes, intitulada "Como virar papai", publicada na Folha de São Paulo de 27/08/2017. Disponível em: http://www1.folha.uol.com br/colunas/reinaldojoselop es/2017/08/1913256-como-virarpapai.shtml?loggedpaywall 
da esfera pública. Por momentos, essas narrativas assumem a forma de uma nova ciência do concreto. Neste contexto, a evocação levistraussiana não é meramente retórica: as apropriações da sociobiologia funcionam como uma bricolagem capaz de provocar os fascínios mais imprevisíveis na "cosmologia ocidental". O próprio Sahlins já nos chamava a atenção sobre a inevitável afinidade eletiva entre esta cosmologia e o ideário sociobiológico (seriam as recentes inquisições contra a presença de Judith Buttler, no Brasil, uma das faces caricatas dessa afinidade?).

A figura da bricolagem pode, também, deixar de ser uma mera metáfora para assumir - tal como tem acontecido recentemente - sua mais pura materialidade e literalidade nas operações de "recorta/cola" (afinal, é dessa maneira que opera o pensamento mítico) inscritas no Requerimento da CPI FUNAI-INCRA 2. Quando o arte-facto em questão (a bricolagem) passa a esgrimir pretensões de "quase" cosmologia, o efeito jurídico se consuma. No entanto, para que essa eficácia instrumental e simbólica se realize plenamente, é necessário que a autoria, individual ou coletiva, passe para um segundo plano. Trata-se, como diria Pierre Bourdieu (2001), do "mistério do ministério".

Todas essas questões têm inúmeros e imprevisíveis desdobramentos. Se, por um lado, é verdade que temos que exercer nossa vigilância epistemológica em relação às investidas neoconservadoras, por outro, não deixa de ser perturbador o fato de que muitas dessas estocadas podem assumir a forma de "verdades científicas" ou de argumentos sociobiológicos como:

os machos produzem grande quantidade de espermatozoides com mobilidade e não realizam a gestação dos filhos, ao passo que as fêmeas produzem pequeno número de óvulos imóveis e fazem a gestação, portanto essas diferenças biológicas autorizam diferenças comportamentais. (Erickson e Murphy, 2013: 217-218)

O que dizer quando essas "verdades" vêm acompanhadas de acusações contra o caráter supostamente anticientífico, militante, obscurantista e ativista da antropologia social ou cultural?

A antropologia se esforçou durante décadas para desbiologizar a cultura. Ao mesmo tempo, em virtude da sua vigorosa vocação anti-obscurantista, soube defender o evolucionismo biológico contra o falso evolucionismo (aquele que, por exemplo, enxerga os Yanomami como nossos contemporâneos "primitivos"). A "Civilização Ocidental", diz Marshall Sahlins na epígrafe, quase em tom de lamento, "foi construída sobre uma ideia perversa e equivocada de natureza humana". $\mathrm{Na}$ sua fracassada tentativa de colonizar a antropologia, a sociobiologia tem sido uma parceira fiel daquela ideia. É preciso estarmos alertas a essas e outras investidas, caso queiramos continuar preservando a integridade da nossa ciência. 
Lorenzo Macagno é professor associado do Departamento de Antropologia da Universidade Federal do Paraná e membro da diretoria da Associação Brasileira de Antropologia (gestão 2017-2018).

\section{REFERÊNCIAS BIBLIOCRÁFICAS}

ABA/Associação Brasileira de Antropologia

2015 Protocolo de Brasília. Laudos antropológicos: condições para 0 exercício de um trabalho científico. Brasília, ABA Publicações.

ALBERT, Bruce e RAMOS, Alcida Rita

1989 "Yanomami Indians and Anthropological

Ethics". Science, vol. 244, n. 4905: 632.

BOURDIEU, Pierre

2001 "Le Mystère du ministère. Des Volontés particulières à la 'volonté générale'". Actes de la recherche en sciences sociales, vol. 140: 7-11.

CARNEIRO DA CUNHA, Manuela et al.

2017 "Indigenous Peoples Boxed in by Brazil's Political Crisis".

HAU. Journal of Ethnographic Theory, vol. 7, n. 2: 403-426.

1989 "Letter to the Editor". Anthropology Newsletter, vol. 30, n. 1: 3.

CHACNON, Napoleon A.

1988 "Life Histories, Blood Revenge, and Warfare in a Tribal

Population". Science, vol. 239, n. 4843: 985-992.

1989 "Letter to the Editor". Anthropology Newsletter, vol. 30, n. 1: 24.

2014 Nobres selvagens. Minha vida entre duas tribos perigosas: os ianomâmis e os antropólogos. São Paulo, Três Estrelas.

\section{CPI FUNAI-INCRA 2}

2016 Requerimento $n^{0}$ 86/2016. Comissão Parlamentar de inquérito destinada a investigar a atuação da Fundação Nacional do Índio (FUNAl) e do Instituto Nacional de Colonização e Reforma Agraria (INCRA) na demarcação de terras indigenas e de remanescentes de quilombos. Brasília, Câmara dos Deputados. 
DALLA COSTA, J. M.; ALVES DE ALMEIDA, R.; e SILVEIRA ANJOS, F.

2016 "A CPI da antropologia". 30 Reunião Brasileira de Antropologia, João

Pessoa. Disponível em: http://www.3orba.abant.org.br/arquivo/

ERICKSON, Paul A. e MURPHY, Liam D.

2013 A History of Anthropological Theory. Toronto, University of Toronto Press.

GEERTZ, Clifford

[2001]2015 "Sobre a devastação da Amazônia". In A vida entre os antros e outros ensaios. Petrópolis, Vozes. pp.137-149. [Artigo publicado, originalmente, sob o título "Life among the Anthros". New York Review of Books, 48, n. 2, 08/02/2001].

HARRIS, Marvin

1978 "Proteins and the Fierce People". In Cannibals and Kings. The Origins ofCultures. Glasgow, Fontana/Collins. pp. 56-64.

1979 "Sociobiology and Biological Reductionism". In Cultural Materialism: The Struggle for a Science of Culture. Nova York, Random House. pp. 119-140.

MARKS, Jon

1980 "Sociobiology, Selfish Cenes, and Human Behavior: A Bio-

Cultural Critique". Arizona Anthropologist [Atlatl], vol. 1: 28-54.

PRICE, David

2013 "An Interview With Marshall Sahlins. The Destruction of Conscience in the National Academy of Sciences". Anuac, vol. II, n. 1:165169. [Originalmente publicado em: counterpunch.org]

RAMOS, Alcida Rita

2004 "Os Yanomami no coração das trevas brancas". Série Antropologia, n. 350. Brasília, DAN/UnB.

SAHLINS, Marshall

1976 The Use and Abuse of Biology. An Anthropological Critique of Sociobiology. Ann Arbor, University of Michigan Press.

2008 The Western Illusion of Human Nature. Chicago, Prickly Paradigm Press.

SILVA, Cláucia de Oliveira da

1993 O que é sociobiologia. Coleção primeiros passos.

São Paulo, Editora Brasiliense. 
Dossı̂̂ | Lorenzo Macagno | Antropologia e sociobiologia:

2006 "A sociobiologia e a crítica dos antropólogos".

ComCiência: Revista Eletrônica de Jornalismo Científico, n.

80. Disponível em: http://www.comciencia.br/

TIERNEY, Patrick

2000 Darkness in El Dorado: How Scientists and Journalists

Devastated the Amazon. Nova York, W. W. Norton.

WILSON, Edward O.

1975 Sociobiology. The New Synthesis. Cambridge/Massachusetts e Londres, The Belknap Press of Harvard University Press. 


\section{ABSTRACT}

At the end of 2016, a Petition issued by members of a Parliamentary Inquiry Committee (CPI), known as CPI FUNAI-INCRA 2, requested the breaking of bank and fiscal confidentiality of the Brazilian Anthropological Association (ABA), and of its president. To support the accusations against the $A B A$, the Petition cited, in one of its passages, arguments of Napoleon A. Chagnon. These included the statement that Brazilian anthropologists are not engaged in science, but in activism. Chagnon was one of the few anthropologists to adopt the postulates of the so-called sociobiology. By evoking the name of Chagnon, the Petition of the CPI was, unwittingly, "reviving" a moribund debate: anthropology versus sociobiology. Based on the accusatory scenario created by the CPI FUNAI-INCRA 2, this article returns to the fundamental debate that has divided anthropologists and sociobiologists since the 1970 s.

\section{KEYWORDS}

Sociobiology, CPIFUNAI-INCRA

2, Napoleon A. Chagnon, Brazilian Anthropology Association, Controversies

Recebido em 18 de fevereiro de 2018. Aceito em 10 de março de 2018. 